С.А. Ушакова ${ }^{1}$, Н.Л. Ащеулова ${ }^{2}$, Л.Н. Конева ${ }^{3}$, О.Ю. Халидуллина ${ }^{1,3}$, О.В. Павлова ${ }^{1,3}$, В.С. Резенова ${ }^{3}$, В.Н. Лукьянова ${ }^{3}$, Э.Э. Фёдорова ${ }^{3}$, М.В. Пшеничникова ${ }^{3}$

1 Тюменская государственная медицинская академия, Тюмень, Российская Федерация

2 Окружная клиническая больница, Салехард, Российская Федерация

3 областная клиническая больница № 1, Тюмень, Российская Федерация

\title{
Эффективное применение
}

\section{моноклональных антител к TNF $\alpha-$ адалимумаба - как препарата переключения у пациента \\ с ювенильным идиопатическим полиартритом и увеитом}

Контактная информация:

Ушакова Светлана Анатольевна, кандидат медицинских наук, доцент кафедры педиатрии ФПК и ППс гБоУ ВПо «Тюменская государственная медицинская академия"

Адрес: 625023, Тюмень, ул. Одесская, д. 54, тел.: +7 (3452) 28-75-13, e-mail: ushakova_tgma@mail.ru

Статья поступила: 04.09.2014 г., принята к печати: 24.11.2014 г.

Представлен случай тяжелого течения ювенильного идиопатического артрита, ассоциированного с увеитом, у пациента, заболевшего в возрасте 10 лет. Увеит дебютировал через 9 мес после манифестации суставного синдрома на фоне терапии этанерцептом. Переключение на адалимумаб индуцировало ремиссию суставного синдрома и увеита. К 8-й нед лечения у ребенка констатирована стадия неактивной болезни, длительность которой составила 6 мес. Ключевые слова: ювенильный идиопатический артрит, увеит, лечение, адалимумаб.

(Педиатрическая фармакология. 2014; 11 (6): 66-72)

\section{ВВЕДЕНИЕ}

Ювенильный идиопатический артрит (ЮИА) - одно из наиболее частых и самых инвалидизирующих ревматических заболеваний, встречающихся у детей [1]. Заболеваемость ЮИА составляет 2-16 на 100 тыс. детского населения в возрасте до 16 лет. На территории Российской Федерации распространенность ЮИА у детей до 18 лет достигает 62,3, первичная заболеваемость - 16,2 на 100 тыс., в том числе у подростков 116,4 и 28,3, у детей до 14 лет - 45,8 и 12,6, соответственно [2, 3].

Согласно современным представлениям, ЮИА - это хроническое аутоиммунное заболевание с неизвестной этиологией и сложным патогенезом, которое неуклонно

S.A. Ushakova ${ }^{1}$, N.L. Achsheyulova ${ }^{2}$, L.N. Koneva ${ }^{3}$, O.Y. Khalidullina ${ }^{1,3}$, 0.V. Pavlova $^{1,3}$, V.S. Rezenova ${ }^{3}$, V.N. Lukyanova ${ }^{3}$, E.E. Fyodorova ${ }^{3}$, M.V. Pshenichnikova ${ }^{3}$

1 Tyumen State Medical Academy, Tyumen, Russian Federation

2 District Clinical Hospital, Salekhard, Russian Federation

${ }^{3}$ Regional Clinical Hospital No. 1, Tyumen, Russian Federation

\section{Effective Use of Monoclonal Antibodies Against TNF $\alpha-$ Adalimumab - as a Switchover Drug in a Patient with Juvenile Idiopathic Polyarthritis and Uveitis}

The article presents a case of severe juvenile idiopathic uveitis-associated arthritis in a patient who contracted the disease at the age of 10 years. Uveitis developed 9 months after manifestation of the articular syndrome in the event of etanercept therapy. Switch to adalimumab induced remission of the articular syndrome and uveitis. By the 8th week of treatment, an inactive disease stage (6 months) was diagnosed in a child.

Key words: juvenile idiopathic arthritis, uveitis, treatment, adalimumab.

(Pediatricheskaya farmakologiya - Pediatric pharmacology. 2014; 11 (6): 66-72) 
прогрессирует и приводит к быстрому развитию инвалидизации больных, снижению качества их жизни, социальной и психологической дезадаптации [4, 5].

В клинической картине разных вариантов ЮИА наряду с артритом могут наблюдаться различные внесуставные проявления болезни, в том числе увеит [2, 3]. Увеит воспаление сосудистой оболочки глаза - одно из наиболее частых и тяжелых экстраартикулярных проявлений ЮИА [6]. Увеит развивается у 12-24\% детей с ЮИА, преимущественно с олигоартикулярным вариантом болезни. Частота необратимого снижения остроты зрения вследствие развития осложнений увеита достигает 12\% и приводит к значительной инвалидизации детей [7].

Лечение детей с офтальмологическими проявлениями ЮИА необходимо начинать рано и достаточно агрессивно. Основа лечения увеита - в первую очередь, максимальное использование методов локальной терапии, осуществляемой офтальмологами [8]. В связи с недостаточной эффективностью местного противовоспалительного лечения значительному числу пациентов требуется назначение иммунодепрессантов и генноинженерных биологических препаратов (ГИБП) [1, 5]. Системную терапию назначают и корректируют ревматологи и офтальмологи, которые должны находиться в тесном контакте. $K$ настоящему времени ревматологи располагают достаточно современным арсеналом средств, позволяющим контролировать патологический процесс у детей с ЮИА. Составляющими лечебного комплекса являются нестероидные противовоспалительные средства (НПВС), иммунодепрессанты, глюкокортикоиды и ГИБП $[1,5]$.

Использование ГИБП, действие которых направлено на подавление эффектов цитокинов, а также других факторов, участвующих в воспалении, имело революционное значение для терапии ревматических заболеваний [9-11]. По данным немногочисленных исследований, эффективность ГИБП, преимущественно ингибиторов фактора некроза опухоли (tumor necrosis factor, TNF) $\alpha$, значительно варьирует у детей с увеитами и составляет от 35 до 100\%, что обусловлено различием критериев отбора больных, успеха терапии, сроков наблюдения, сопутствующего лечения, малым числом пациентов [12-14]. Вместе с тем в большинстве публикаций подчеркиваются хорошие результаты, относительно небольшая частота побочных реакций и целесообразность назначения биологических препаратов при недостаточной эффективности традиционной иммуносупрессивной терапии [15-17]. Наиболее эффективным при увеите из применяемых в настоящее время препаратов является адалимумаб [18-20].

\section{КЛИНИЧЕСКИЙ ПРИМЕР}

Приводим собственное наблюдение эффективного и хорошо переносимого лечения адалимумабом в качестве препарата переключения у ребенка с полиартикулярным ювенильным артритом, осложнившимся увеитом через 9 мес после дебюта суставного синдрома.

Пациент А., 12 лет, наблюдается ревматологами областной клинической больницы № 1 (ОКБ № 1) г. Тюмени с января 2013 г. с диагнозом «Ювенильный идиопатический полиартрит, серонегативный по ревма- тоидному фактору, с поражением глаз - двусторонний увеит в ремиссии, рентгенологическая стадия I, функциональный класс I». С февраля 2013 г. больной курируется специалистами ревматологического отделения Научного центра здоровья детей (НЦЗД, Москва), с марта 2014 г. нИИ глазных болезней им. Гельмгольца (Москва).

Ребенок родился от 1-й беременности, протекавшей на фоне железодефицитной анемии, угрозы прерывания в 4 мес; 1-х оперативных родов в связи с преждевременным излитием околоплодных вод и родовой слабостью. Масса тела при рождении составила 4450 г; закричал сразу. При рождении выявлена синдактилия III-IV пальцев правой стопы. Вакцинация проводилась по национальному календарю. Из перенесенных заболеваний: острые респираторные инфекции - 2-3 раза в год, ветряная оспа, конъюнктивит, аденоидит, подчелюстной лимфаденит. Наследственность по аутоиммунным ревматическим заболеваниям не отягощена, у отца - подагра. В семейном анамнезе по линии отца у многих родственников - сахарный диабет 2-го типа.

Ребенок заболел в возрасте 10 лет в декабре 2012 г. Заболеванию предшествовали травма стопы (подвернул ногу во время игры в футбол, боль в области стопы прошла быстро, самостоятельно), периодические боли в животе и жидкий стул с повышением температуры тела до $38,6^{\circ} \mathrm{C}$ в течение 2 нед. Заболевание началось остро: 17.12.2012 г. утром не смог встать на ноги из-за боли в левом голеностопном суставе; на следующий день в области сустава появились отечность и гипертермия. Температура тела не повышалась. Экстренно госпитализирован по месту жительства в хирургическое отделение с диагнозом "Артрит левого голеностопного сустава». Ребенок получал антибактериальный препарат ампициллин + сульбактам. Через 1 нед мальчик был переведен в инфекционное отделение в связи с появившимся жидким стулом, субфебрильной температурой тела. Моноартрит сохранялся. По результатам обследования выставлен диагноз "Хроническая стрептококковая инфекция. Острый артрит левого голеностопного сустава. Антибиотикассоциированная диарея". В клиническом анализе крови: нейтрофильный лейкоцитоз (3 нормы), ускорение СОЭ до 40 мм/ч, высокий уровень С-реактивного белка (СРБ; 3 нормы). При бактериологическом исследовании слизи из зева выделен гемолитический стрептококк.

Ребенок получал антибиотики (цефотаксим, линкомицин), НПВС (ибупрофен); был выписан через 7 дней в связи с отказом родителей от стационарного лечения с рекомендациями продолжить терапию цефотаксимом и нимесулидом.

В течение 3 дней наблюдалось кратковременное улучшение самочувствия. С 04.01.2013 г. отмечено ухудшение состояния: температура тела повысилась до $38,5^{\circ} \mathrm{C}$, в процесс были вовлечены новые суставы (появились боль, отек и гиперемия в правом голеностопном суставе и I пальце правой кисти). Ребенок был экстренно госпитализирован в детское отделение по месту жительства, где находился в течение 5 дней с предположительным диагнозом «Ювенильный ревматоидный артрит, суставная форма". 
При обследовании сохранялись высокие лабораторные показатели активности: нейтрофильный лейкоцитоз (1,5 нормы), СОЭ (6 норм), высокие сывороточные уровни СРБ (2 нормы) и фибриногена (2 нормы). Антитела к стрептококку в сыворотке крови не определялись. По данным рентгенографии левого голеностопного сустава патологии не выявлено. Ребенку проводилась антибактериальная терапия амоксициллином клавуланатом внутрь, также получал НПВП нимесулид; был назначен преднизолон внутрь в дозе 30 мг/сут в течение 3 дней. Эффекта от проводимой терапии не было. Родители от лечения в стационаре по месту жительства отказались и 11.01.2013 г. самостоятельно обратились в приемное отделение ОКБ № 1 г. Тюмени.

Мальчик экстренно госпитализирован в детское специализированное отделение по оказанию помощи детям с ревматическими заболеваниями. При поступлении ребенок жаловался на боль и отек в пораженных суставах, утреннюю скованность длительностью до 4 ч, невозможность передвигаться из-за боли. У пациента отмечалась субфебрильная лихорадка до $37,8^{\circ} \mathrm{C}$. Состояние по заболеванию расценено как тяжелое. Суставной синдром носил полиартикулярный характер с преимущественным поражением суставов нижних конечностей: выраженные экссудативно-пролиферативные изменения в голеностопных суставах, в области стоп, межфаланговых суставах II пальца правой стопы и I пальца правой кисти; резкое ограничение функции пораженных суставов. При наблюдении за ребенком в течение первой недели отмечено вовлечение в патологический процесс новых суставов: появились воспалительные изменения и ограничение движений в левом лучезапястном и левом локтевом суставах.

По результатам проведенного исследования в клиническом анализе крови выявлено повышение СОЭ до 70 мм/ч, анемия средней степени (гемоглобин 86 г/л), лейкоцитоз $\left(11,9 \times 10^{9} / л\right)$, тромбоцитоз $\left(501 \times 10^{9} / л\right)$; высокий сывороточный уровень СРБ (10 норм). Прокальцитониновый тест - отрицательный. Иммуноферментный анализ IgM, IgG на Chlamydia trachomatis - отрицательный. Серологические реакции на кишечную группу сальмонеллез-шигеллез-псевдотуберкулез - отрицательные; на иерсиниоз титр составил 1:6400 (в парных сыворотках). Ревматоидный фактор, антинуклеарный фактор и антитела к ДНК в сыворотке крови не выявлялись; HLA-B27 - отрицательный.

По данным ультразвукового исследования (УЗИ) голеностопных суставов: тыльный синовиальный заворот расширен с обеих сторон; справа суставная щель расширена за счет избыточного количества свободной жидкости по латеральной поверхности, утолщены капсула и сухожилия латеральной группы с наличием жидкости в синовиальном влагалище; слева внутрисуставная жидкость однородная в незначительном количестве, сухожилия латеральной и медиальной группы утолщены с наличием жидкости в синовиальном влагалище. По Узи лучезапястных суставов: суставная щель слева несколько расширена из-за избыточного количества внутрисуставной жидкости, капсула не утолщена, связочный аппарат не изменен. По данным УзИ локтевых суставов: гиалиновый хрящ слева неоднородной структуры, суставная щель слева расширена из-за избыточного количества внутрисуставной жидкости, капсула не утолщена, свободная жидкость в ямке локтевого отростка слева; синовиальная оболочка слева неравномерно утолщена. По данным УзИ коленных и тазобедренных суставов, рентгенографии голеностопных суставов, органов грудной полости, электрокардиографии, эхокардиографии, УзИ органов брюшной полости патологических изменений не выявлено. По данным осмотра окулиста увеит исключен. Консультация инфекциониста: учитывая предшествовавшее полиартриту заболевание с лихорадкой, болями в животе и жидким стулом, высокие титры с иерсиниозным диагностикумом, имеет место иерсиниоз, период реконвалесценции.

Длительность артрита у пациента на момент поступления в детское отделение ОКБ № 1 составляла 3-4 нед, и заболевание исходно расценивалось нами как реактивный полиартрит с высокой активностью воспаления, ассоциированный с перенесенной кишечной иерсиниозной инфекций. Проводимое в отделении лечение включало антибиотики (последовательно цефтриаксон, амикацин, ципрофлоксацин), нестероидные противовоспалительные средства (Диклофенак натрия внутримышечно 3 дня, затем нимесулид). Учитывая длительность заболевания в течение 4 нед, включение в процесс новых суставов, выраженную активность воспаления и высокий риск хронизации артрита, с 16.01.2013 г. назначен сульфасалазин с постепенным повышением дозы до 1,5 г/сут. Состояние ребенка по заболеванию оставалось тяжелым за счет сохраняющейся высокой активности воспалительного процесса. Эффекта от проводимой терапии не отмечалось.

Проведена дистанционная телемедицинская консультация пациента со специалистами ревматологического отделения НЦЗД. Рекомендовано дополнительное обследование с целью исключения злокачественных новообразований (лейкоза, лимфом, солидных опухолей). Выполнена стернальная пункция с исследованием миелограммы (недифференцируемые бластные клетки 1,8\%, повышенная клеточность за счет нейтрофильного ростка): острый лейкоз исключен. По результатам компьютерной томографии органов грудной и брюшной полости были исключены онкологические процессы. Учитывая длительность заболевания (> 6 нед), наиболее вероятным был диагноз ювенильного идиопатического полиартрита. В связи с сохраняющейся высокой активностью болезни, резистентностью к проводимой терапии, ребенок направлен в федеральный центр для определения дальнейшей тактики лечения.

В феврале 2013 г. пациент А. впервые госпитализирован в ревматологическое отделение НЦЗД. По результатам комплексного обследования верифицирован диагноз: "Юношеский полиартрит серонегативный. Активность III-II степени. Функциональный класс I. Рентгенологическая стадия I". В клиническом анализе крови отмечена тенденция к снижению СОЭ до 48 мм/ч. Сохранялись высокие положительные титры с иерсиниозным диагностикумом - 285 усл. ед. (норма 0-20). 
Таблица. Динамика клинических и лабораторных показателей активности болезни у пациента А. на фоне проводимой терапии

\begin{tabular}{|c|c|c|c|c|c|c|c|c|}
\hline \multirow{3}{*}{ Показатели } & \multirow{3}{*}{01.2013} & \multirow{3}{*}{02.2013} & 06.2013 & 07.2013 & 08.2013 & 09.2013 & 03.2014 & 11.2014 \\
\hline & & & \multicolumn{4}{|c|}{ Терапия этанерцептом } & \multicolumn{2}{|c|}{ Терапия адалимумабом } \\
\hline & & & Исходно & $\begin{array}{l}\text { Через } \\
4 \text { нед }\end{array}$ & $\begin{array}{l}\text { Через } \\
8 \text { нед }\end{array}$ & $\begin{array}{l}\text { Через } \\
12 \text { нед }\end{array}$ & Исходно & $\begin{array}{l}\text { Через } \\
8 \text { мес }\end{array}$ \\
\hline $\begin{array}{l}\text { Длительность утренней } \\
\text { скованности, мин }\end{array}$ & 240 & 180 & 120 & 15 & 0 & 0 & 0 & 0 \\
\hline Число припухших суставов & 7 & 7 & 5 & 0 & 0 & 0 & 0 & 0 \\
\hline Число болезненных суставов & 7 & 7 & 5 & 0 & 0 & 0 & 0 & 0 \\
\hline $\begin{array}{l}\text { Число суставов } \\
\text { с ограничением функции }\end{array}$ & 7 & 7 & 5 & 1 & 0 & 0 & 0 & 0 \\
\hline СОЭ, мм/ч & 70 & 48 & 28 & 15 & 4 & 20 & 8 & 6 \\
\hline СРБ, мг/л (норма < 5) & 50,5 & 35,2 & 12,5 & 3,5 & 0,7 & 0,8 & 0 & 0 \\
\hline Эритроциты, × 10²/л & 3,9 & 4,1 & 4,6 & 4,9 & 4,8 & 4,9 & 4,6 & 4,7 \\
\hline Гемоглобин, г/л & 96 & 91 & 105 & 120 & 120 & 117 & 126 & 125 \\
\hline Лейкоциты, ×109/л & 11,9 & 6,8 & 8,1 & 7,5 & 7,2 & 10,0 & 8,8 & 7,3 \\
\hline Тромбоциты, ×109/л & 501 & 468 & 354 & 330 & 345 & 311 & 325 & 299 \\
\hline Увеит & \multicolumn{5}{|c|}{ Без поражения органа зрения } & $\begin{array}{l}\text { Увеит } \\
\text { острый }\end{array}$ & $\begin{array}{c}\text { Увеит } \\
\text { хронический } \\
\text { вялотекущий }\end{array}$ & Ремиссия \\
\hline Проводимая терапия & \multicolumn{2}{|c|}{$\begin{array}{c}\text { Сульфасалазин } \\
\text { по } 1500 \text { мг/сут } \\
\text { НПВС - ежедневно }\end{array}$} & \multicolumn{3}{|c|}{$\begin{array}{c}\text { Сульфасалазин } \\
\text { по } 1500 \text { мг/сут } \\
\text { НПВС - при боли }\end{array}$} & \multicolumn{2}{|c|}{$\begin{array}{l}\text { Метотрексат } \\
\text { по } 18 \text { мг/нед }\end{array}$} & $\begin{array}{l}\text { Метотрексат } \\
\text { по } 10 \text { мг/нед }\end{array}$ \\
\hline ГИБП & & & \multicolumn{4}{|c|}{ Этанерцепт по 30 мг/нед } & \multicolumn{2}{|c|}{ Адалимумаб по 40 мг/нед } \\
\hline $\begin{array}{l}\text { Эффективность лечения } \\
\text { по критериям АКР педи }\end{array}$ & & $<30 \%$ & $30 \%$ & $90 \%$ & $\begin{array}{c}\text { Неактивная } \\
\text { болезнь }\end{array}$ & \multicolumn{2}{|c|}{$\begin{array}{c}\text { Активная болезнь } \\
\text { (увеит) }\end{array}$} & Ремиссия \\
\hline Масса тела, кг & 38 & \multirow{2}{*}{\multicolumn{6}{|c|}{-}} & 50 \\
\hline Длина тела, см & 138 & & & & & & & 145 \\
\hline
\end{tabular}

Примечание. СОЭ - скорость оседания эритроцитов, СРБ - С-реактивный белок, ГИБП - генно-инженерные биологические препараты, АКР педи - педиатрические критерии Американской коллегии ревматологов для оценки эффективности лечения.

Были получены отрицательные результаты исследований на вирусы гепатитов В и С, Эпштейна-Барр, а также вирусы герпетической группы, токсоплазмоз и микоплазмоз. При компьютерной томографии изменений со стороны илеосакральных сочленений не выявлено; в головке правой бедренной кости определен единичный субхондральный дефект (вероятнее всего, эрозивный) до 2 мм глубиной. На рентгенограмме кистей слева и справа выявлялись сглаженность контура мягких тканей в области лучезапястных суставов, повышенная прозрачность костных структур, немногочисленные кистовидные просветления костной ткани, неровность контуров суставных поверхностей; сужение суставных щелей не обнаружилось.

В ревматологическом отделении состояние ребенка оставалось стабильным. На фоне продолжающейся более 4 нед терапии сульфасалазином и нимесулидом купировалась боль, длительность утренней скованности сократилась до 3 ч, уменьшились экссудативно-пролиферативные проявления, нарос объем движений в пораженных суставах. Было решено продолжить терапию сульфасалазином в дозе 1,5 г/сут (из расчета 39 мг/кг массы тела).
При динамическом наблюдении (табл.) через 3 мес от начала терапии сульфасалазином у пациента достигнуто 30\% улучшение по педиатрическим критериям Американской коллегии ревматологов (АКР педи). Длительность утренней скованности уменьшилась до 2 ч, но сохранялись суставы с активным воспалением, и персистировало повышение лабораторных показателей.

Учитывая недостаточную эффективность проводимой терапии, в июне 2013 г. в ревматологическом отделении НЦЗД инициирована терапия биологическим препаратом этанерцепт (растворимые рецепторы к TNF $\alpha$ ) в дозе 30 мг/нед подкожно. Перед назначением ингибитора TNF $\alpha$ ребенку были выполнены компьютерное исследование органов грудной полости, реакция Манту и Диаскинтест для исключения туберкулезного процесса. Уже через 1 нед от начала лечения этанерцептом отмечена положительная динамика: длительность утренней скованности сократилась до 30 мин, уменьшились воспалительные изменения, и увеличился объем движений в суставах. Через 4 нед после первой инъекции этанерцепта зарегистрировано $70 \%$, а через 12 нед терапии - 90\% улучшение по критериям АКР педи. 
Однако, в сентябре 2013 г. у мальчика развился острый увеит. В экстренном порядке ребенок был госпитализирован в отделение офтальмологии по месту жительства с жалобами на покраснение, светобоязнь, снижение зрения правого глаза. Офтальмологический статус: Visus 0,5/1,0. OD - светобоязнь, блефароспазм, умеренный отек век, глаз раздражен, смешанная инъекция глазного яблока, роговица отечная, на эндотелии единичные преципитаты серого цвета, передняя камера средней глубины, влага прозрачная, радужка отечная, зрачок круглый, узкий, по зрачковому краю - фибрин, синехии, после циклоплегии - незначительно расширился, по всей окружности - множественные задние синехии, по передней капсуле хрусталика - фибрин, рефлекс с глазного дна слабо-розовый, глазное дно за "флером", детали глазного дна офтальмоскопируются с трудом. OS - спокоен.

Лечение увеита включало инстилляции дексаметазона, НПВП-содержащих капель, мидриатиков короткого действия, мидриацилсодержащих глазных капель.

Ребенок проконсультирован ревматологом. Учитывая развитие увеита, проведена коррекция базисной противоревматической терапии: сульфасалазин отменен, назначен метотрексат подкожно в дозе 18 мг/нед (из расчета 15 мг/м² поверхности тела в нед), продолжено лечение этанерцептом в прежней дозе. На фоне терапии в течение первых 2 нед достигнута положительная динамика, но в дальнейшем поражение органа зрения стало двусторонним и приняло вялотекущий характер. Суставной синдром был вне обострения.

В марте 2014 г. при госпитализации в ревматологическое отделение НЦЗД проконсультирован специалистом НИИ глазных болезней им. Гельмгольца с заключением "Вялотекущий двусторонний увеит". В связи с неэффективностью предшествующей терапии пациенту А. этанерцепт был отменен, назначен адалимумаб подкожно в стандартной дозе 40 мг 1 раз в 2 нед. Рекомендована местная терапия, фоновым препаратом оставлен метотрексат. Комплексное лечение продолжено (без перерывов) в поликлинике по месту жительства под контролем педиатра, ревматолога и офтальмолога.

Анализ эффективности терапии показал, что через 2 мес от начала лечения адалимумабом у пациента А. достигнута неактивная стадия увеита, а через 8 мес (см. табл.) в соответствии с критериями Краскела-Уоллиса констатирована фармакологическая ремиссия ЮИА: отсутствие увеита (по данным осмотра офтальмологом), утренней скованности, суставов с активным артритом и ограничением функции; нормальные показатели СОЭ и СРБ, отсутствие активности болезни и нарушения самочувствия ребенка по визуальной аналоговой шкале. Ребенку было проведено контрольное УзИ голеностопных, лучезапястных и локтевых суставов. По данным УЗИ: суставные поверхности ровные, четкие; кортикальный слой однородной структуры; внутрисуставная жидкость однородная, в незначительном количестве; суставная щель не изменена; капсула и синовиальная оболочка не утолщены. По данным рентгенографии голеностопных и тазобедренных суставов: суставные щели симметричные; суставные поверхности ровные, четкие; костные структуры не изменены. Физическое развитие мальчика соответствует возрастным нормативам.

Переносимость лечения адалимумабом у ребенка хорошая. Нежелательных явлений со стороны клинических и лабораторных (гематологических и биохимических) показателей не зарегистрировано. За прошедшие 8 мес от начала введения адалимумаба ребенок перенес эпизод лабиального герпеса и две острые респираторные инфекции в легкой форме. Через 6 мес выполнены контрольное компьютерное исследование органов грудной полости и квантифероновый тест (реакции Манту и Диаскинтест не проводили в связи с увеитом): исключен туберкулезный процесс. Учитывая эффективность лечения, достижение критериев ремиссии и хорошую переносимость, терапия адалимумабом в дозе 40 мг подкожно 1 раз в 2 нед продолжена. Доза метотрексата снижена до 10 мг/нед. Пациент А. посещает общеобразовательную школу, принимает активное участие в жизни классного коллектива, играет со сверстниками в подвижные игры, что в целом свидетельствует об оптимальном качестве жизни ребенка.

\section{ОБСУЖДЕНИЕ}

Значительное число пациентов с ЮИА в период дебюта увеита уже получают иммунодепрессанты в связи с выраженностью суставного синдрома. В настоящее время основными препаратами для системного лечения ЮИА-ассоциированных увеитов остаются глюкокортикоиды, циклоспорин и метотрексат [8]. Однако, их эффективность при увеите, даже при комбинированном применении, не превышает 48-71\%, а назначение нередко сопровождается развитием побочных реакций $[14,20]$. Многочисленными исследованиями установлена эффективность ГИБП в лечении ЮИА, при этом их влияние на течение ассоциированного увеита изучено лишь в небольших группах пациентов, а пролученные результаты неоднозначны [12, 21].

У наблюдаемого нами пациента ЮИА уже в дебюте характеризовался факторами неблагоприятного прогноза течения: полиартикулярный характер поражения опорно-двигательного аппарата с развитием функциональной недостаточности, высокая активность воспалительного процесса [2, 3]. Рано начатая терапия сульфасалазином позволила достичь через 12 нед 30\% улучшения по критериям АКР педи. Недостаточная эффективность терапии послужила основанием для инициации лечения этанерцептом (растворимым рецептором к TNF $\alpha$ ) [1]. Уже через 4 нед после первой инъекции ингибитора TNF $\alpha$ зарегистрировано 70\% улучшение по критериям АКР педи, через 12 нед - 90\%. Однако, вскоре на фоне продолжающейся терапии в отсутствии обострения суставного синдрома у ребенка развился острый правосторонний увеит, который манифестировал спустя 9 мес после дебюта полиартикулярного суставного синдрома, когда ребенок уже получал сульфасалазин и ингибитор TNF (этанерцепт). При этом развитие увеита не коррелировало с активностью артрита, что совпадает с данными литературы $[7,12]$. Лечение у офтальмологов включало активную местную терапию увеита с инстилляцией кортикостероидных и НПВС-содержащих глазных капель. Проводилась 
коррекция базисной противовоспалительной терапии ЮИА: сульфасалазин был отменен, и назначен метотрексат подкожно, продолжено введение этанерцепта. Несмотря на проводимое лечение, в течение последующих 6 мес сформировался хронический вялотекущий двусторонний увеит со снижением остроты зрения. Пациенту требовалась коррекция проводимой терапии для индукции ремиссии увеита [1]. В связи с неэффективностью лечения этанерцептом в ревматологическом отделении НЦЗД проведено переключение на второй ГИБП - адалимумаб (рекомбинатные моноклональные антитела к TNF $\alpha$ ) в дозе 40 мг 1 раза в 2 нед.

Анализ эффективности терапии адалимумабом уже через 2 мес лечения показал, что у пациента А. с ЮИА достигнут статус неактивной болезни по увеиту и полностью восстановлена функция пораженных суставов. Спустя 8 мес от начала лечения препаратом констатирована ремиссия болезни. В настоящий момент мальчик продолжает получать адалимумаб в дозе 40 мг подкожно 1 раз в 2 нед, доза меторексата снижена до 10 мг/нед. Введение препарата проходит без развития нежелательных реакций, инъекции пациент переносит хорошо.

Адалимумаб - представитель группы ингибиторов (блокаторов) TNF $\alpha$, в настоящее время являющихся основными биологическими препаратами для лечения ЮИА без системных проявлений. Адалимумаб представляет собой рекомбинантные моноклональные антитела, пептидная последовательность которых идентична IgG1 человека. Препарат получен путем рекомбинантной ДНК-технологии и имеет высокую аффинность к p55 и р75 рецепторам растворимого и связанного с мембранами TNF $\alpha$. Адалимумаб может вызывать активацию системы комплемента, что приводит к лизису клеток, на поверхности которых находится TNF $\alpha$. Адалимумаб вводится подкожно 1 раз в 2 нед (период его полураспада составляет 2 нед), что определяет возможность удобного для большинства пациентов применения препарата в амбулаторных условиях [1, 2]. В Российской Федерации у детей с ювенильным идиопатическим артритом адалимумаб зарегистрирован с возраста 4 лет. Возможно применение адалимумаба как в комбинации с метотрексатом, так и в качестве монотерапии [1].

Контролируемые клинические исследования показали, что адалимумаб эффективен у детей с ЮИА, в том числе при сопутствующем увеите [10]. Несмотря на убедительные доказательства высокой эффективности адалимумаба, полученные в результате клинических исследований и практического применения препарата в Европе и США, наибольший интерес представляет собственный отечественный опыт использования того или иного метода лечения [22]. Результаты российских клинических исследований эффективности и безопасности адалимумаба у пациентов с ЮИА и артритом с поражением глаз, рефрактерным к терапии классическими иммунодепрессантами, демонстрируют его высокую эффективность и безопасность как в качестве препарата первого выбора, так и препарата переключения при неэффективности первого ГИБП [18-20]. Многочисленные наблюдения из реальной клинической практики также свидетельствуют о высокой эффектив- ности своевременно назначенной патогенетически обоснованной биологической терапии адалимумабом для предупреждения инвалидизации больных ЮИА по состоянию суставов и органа зрения [23-25].

В исследовании, проведенном в НИИ глазных болезней им. Гельмгольца [26], изучена эффективность включения ГИБП в схему комплексного лечения у 92 детей в возрасте от 2 до 17 лет с увеитом различной степени тяжести, ассоциированным с ревматической патологией, преимущественно с различными подтипами ЮИА. Назначение ГИБП было инициировано ревматологами ведущих научно-исследовательских учреждений Москвы: детского отделения ФГБУ “НИИР" (руководитель - канд. мед. наук И. П. Никишина), ревматологического отделения НЦЗД (руководитель - проф. Е.И. Алексеева), университетской детской клинической больницы Первого МГМУ им. И. М. Сеченова (директор проф. Н.А. Геппе). Биологические препараты применялись, как правило, в составе комплексной системной терапии. Большинство пациентов получали ингибиторы TNF $\alpha$ (инфликсимаб и адалимумаб). Сроки наблюдения составили от 1,5 до 49 мес; 23 пациента получали последовательно от двух до пяти ГИБП. Ремиссия увеита на фоне лечения адалимумабом отмечалась достоверно чаще, чем при использовании инфликсимаба (45,5 и 21\%, соответственно; $p<0,05)$, при сравнимой тяжести заболевания в выделенных группах. Положительная динамика отмечена еще у $38,6 \%$ больных с активным воспалением в период начала терапии. Лечение адалимумабом обеспечивало благоприятные результаты при любой тяжести увеита. Адалимумаб признан наиболее эффективным из применяемых в настоящее время ГИБП при увеите, ассоцированном с ЮИА. В исследовании описаны случаи дебюта увеита на фоне применения инфликсимаба и этанерцепта. Обоснована необходимость дальнейших исследований эффективности ГИБП у детей при увеитах, ассоциированных с ревматическими заболеваниями, для определения критериев успеха, дифференцированных показаний и схем терапии [26, 27].

\section{ЗАКЛЮЧЕНИЕ}

Появление генно-инженерных биологических препаратов в арсенале детского врача-ревматолога значительно изменило прогноз такого тяжелого инвалидизирующего заболевания как ювенильный идиопатический артрит. Приведенное клиническое наблюдение свидетельствует о высокой эффективности и хорошей переносимости ингибитора TNF $\alpha$ - адалимумаба, позволившего добиться успеха после предшествующей неэффективной традиционной базисной противовоспалительной терапии и лечения растворимыми рецепторами к TNF $\alpha$ - этанерцептом. Индукция ремиссии увеита у нашего пациента позволяет считать адалимумаб перспективным препаратом для лечения рефрактерных к стандартной терапии увеитов у детей.

\section{КОНФЛИКТ ИНТЕРЕСОВ}

Авторы данной статьи подтвердили отсутствие финансовой поддержки исследования/конфликта интересов, который необходимо обнародовать. 


\section{СПИСОК ЛИТЕРАТУРЫ}

1. Баранов А.А., Алексеева Е.И., Бзарова Т.М., Валиева С.И., Денисова Р.В., Исаева К.Б., Карагулян Н.А., Литвицкий П.Ф., Митенко Е.В., Слепцова Т.В., Фетисова А.Н., Чистякова Е.Г., Тайбулатов Н.И., Морев С.Ю. Протокол ведения пациентов с ювенильным артритом. Вопросы современной педиатрии. 2013; 12 (1): $37-56$

2. Алексеева Е. И., Литвицкий П. Ф. Ювенильный ревматоидный артрит: этиология, патогенез, клиника, алгоритмы диагностики и лечения: рук. для врачей, преподавателей, науч. сотр. Под общ. ред. А. А. Баранова. Москва: ВЕДИ. 2007. 368 с.

3. Валиева С.И. Автореф. докт. дисс. Новые технологии в лечении системного ювенильного идиопатического артрита. 2014. 364 с.

4. Малиевский В.А. Качество жизни детей с ювенильным идиопатическим артритом. Вопросы современной педиатрии. Приложение "Ревматические болезни". 2006; 5 (2): 5-11.

5. Никишина И.П., Кузьмина Н.Н. Современная фармакотерапия ювенильных артритов. Вестник Российской академии медицинских наук. 2008; 6: 41-48.

6. Vitale A.T., Graham E., de Boer J.H. Juvenile idiopathic arthritisassociated uveitis: clinical features and complications, risk factors for severe course, and visual outcome. Ocul Immunol Inflamm. 2013 Dec; 21 (6): 478-85. Doi: 10.3109/09273948.2013: 815785.

7. Heiligenhaus A., Heinz C., Edelsten C., Kotaniemi K., Minden K. Review for disease of the year: epidemiology of juvenile idiopathic arthritis and its associated uveitis: the probable risk factors. Ocul Immunol Inflamm. 2013; 21 (3): 180-191. Doi: 10.3109/09273948.2013.791701.

8. Салугина С.О., Фёдоров Е.С. Современные подходы к терапии ювенильных артритов. Фарматека. 2013; 20: 42-48.

9. Баранов А.А., Алексеева Е.И., Валиева С.И., Бзарова Т.М., Митенко Е.В., Денисова Р.В., Фетисова А.Н., Слепцова Т.В., Исаева К.Б., Чистякова Е.Г., Тайбулатов Н.И., Чомахидзе А.М. Терапия генно-инженерными биологическими препаратами: эффективность и безопасность переключения. Вопросы современной педиатрии. 2014; 13 (1): 33-50.

10. Horneff $\mathrm{G}$. Update on biologicals for treatment of juvenile idiopathic arthritis. Expert Opin Biol Ther. 2013 Mar; 13 (3): 361 76. Doi: $10.1517 / 14712598.2013 .735657$.

11. Stoll M.L., Cron R.Q. Treatment of juvenile idiopathic arthritis: a revolution in care. Pediatr Rheumatol Online J. 2014 Apr 23; 12: 13. Doi: 10.1186/1546-0096-12-13.

12. Нероев В.В., Катаргина Л.А., Денисова Е.В. Результаты и перспективы применения генно-инженерных биологических препаратов в лечении эндогенных увеитов у детей. Российский офтальмологический журнал. 2012; 2: 39-44.

13. Heiligenhaus A., Michels H., Schumacher C. et al. Evidencebased, interdisciplinary guidelines for anti-inflammatory treatment of uveitis associated with juvenile idiopathic arthritis. Rheumatology International. 2012; 32 (5): 1121-1133.

14. Qian Y., Acharya N.R. Juvenile idiopathic arthritis-associated uveitis. Curr Opin Ophthalmol. 2010. Nov; 21 (6): 468-72. Doi: 10.1097/ICU.0b013e32833eab83.

15. Garcia-De-Vicuna C., Diaz-Llopis M., Salom D., Bou R., DiazCascajosa J., Cordero-Coma M., Ortega G., Ortego-Centeno N., Suarez-De-Figueroa M., Cruz-Martinez J., Fonollosa A., Blanco R., Garcia-Aparicio A. M., Benitez-Del-Castillo J. M., Anton J. Usefulness of Adalimumab in the Treatment of Refractory Uveitis Associated with Juvenile Idiopathic Arthritis. Mediators Inflamm. 2013. Published online Dec 30, 2013. Doi: 10.1155/2013/560632.

16. Simonini G., Taddio A., Cattalini M. et al. Prevention of flare recurrences in childhood-refractory chronic uveitis: an open-label comparative study of adalimumab versus infliximab. Arthritis Care and Research. 2011; 63 (4): 612-618.

17. Kotaniemi K., Saila H., Kautiainen H. Long-term efficacy of adalimumab in the treatment of uveitis associated with juvenile idiopathic arthritis. Clinical Ophthalmology. 2011; 5 (1): 1425-1429. 18. Алексеева Е.И., Лисицин А. О., Карагулян Н.А., Ломакина О.Л., Валиева С.И., Бзарова Т. М., Денисова Р. В., Гудкова Е. Ю., Чомахидзе А. М., Исаева К.Б. Адалимумаб: новые возможности лечения ревматических болезней. Вопросы современной педиатрии. 2009; 8 (3): 20-26.

19. Алексеева Е.И., Митенко Е.В., Валиева С.И., Бзарова Т.М., Денисова Т.В., Исаева К.Б., Слепцова Т.В., Ч Чомахидзе А. М. Эффективность и безопасность терапии адалимумабом у детей с ювенильным идиопатическим артритом и увеитом. Вопросы современной педиатрии. 2012; 11 (1): 111-118.

20. Жолобова Е. С., Галстян Л.А., Николаева М.Н., Лоскутова О. Ю. Эффективность адалимумаба при лечении ювенильного идиопатического артрита с увеитом. Педиатрия. 2014; 5: 66-71.

21. Pilly B., Heath G., Tschuor P., Lightman S., Gale R.P. Overview and recent developments in the medical management of paediatric uveitis. Expert Opin Pharmacother. 2013 Sep; 14 (13): 1787-95. Doi: $10.1517 / 14656566.2013 .816677$

22. Лучихина Е.Л., Каратеев Д.Е., Насонов Е.Л. Первый опыт применения адалимумаба в России: предварительные результаты 24-недельного открытого исследования. Научно-практическая ревматология. 2008; 5: 59-63.

23. Никишина И. П., Арсеньева С. В., Алексеев Д. Л., Смирнов А. В. Пауциартикулярный юношеский артрит с АНФ-ассоциированным увеитом: клиническое наблюдение семейного случая у матери и дочери с исходом в анкилозирующий спондилит у матери. Педиатрическая фармакология. 2014; 11 (1): 44-50.

24. Алексеева Е.И., Исаева К.Б., Денисова Р.В., Слепцова Т.В., Валиева С.И., Бзарова Т.М., Митенко Е.В., Чомахидзе А.М. Опыт применения моноклональных антител к TNF $\alpha-$ адалимумаба - у ребенка с ювенильным идиопатическим артритом. Педиатрическая фармакология. 2013; 10 (4): 149-153.

25. Малиевский В.А., Нижевич А.А., Первушина Е.П., Сапроно ва Л.Ю. Опыт применения адалимумаба у больной ювенильным артритом с увеитом на фоне болезни Крона. Вопросы современной педиатрии. 2013; 12 (4): 181-184.

26. Нероев В.В., Катаргина Л.А., Денисова Е. В., Старикова А. В., Любимова Н.В. Эффективность генно-инженерных биологических препаратов в лечении увеитов, ассоциированных с ревматическими заболеваниями у детей. Научно-практическая ревматология. 2012; 53 (4): 91-95.

27. Ramanan A. V., Dick A. D., Benton D., Compeyrot-Lacassagne S., Dawoud D., Hardwick B., Hickey H., Hughes D., Jones A., Woo P., Edelsten C., Beresford M.W. A randomised controlled trial of the clinical effectiveness, safety and cost-effectiveness of adalimumab in combination with methotrexate for the treatment of juvenile idiopathic arthritis associated uveitis (SYCAMORE Trial). Trials. 2014 Jan 9; 15: 14. Doi: 10.1186/1745-6215-15-14. 